\title{
Erratum to: Rapid prototyping assisted surgery planning
}

\author{
Chee Kai Chua $^{1} \cdot$ Siaw Meng Chou ${ }^{1} \cdot$ Sing Ching Lin ${ }^{1} \cdot$ Kee Hoe Eu ${ }^{2} \cdot K_{0 k}$ Fah Lew $^{2}$
}

Published online: 2 July 2016

(C) Springer-Verlag London 2016

Erratum to: Int J Adv Manuf Technol Volume 14, Issue 9, pp 624-630

DOI 10.1007/BF01192281

In the version of this article initially published, the given name and family name of the authors were interchanged and the order of authors were incorrect. The correct names and author order are presented in this paper.

The online version of the original article can be found at http://dx.doi. org/10.1007/BF01192281.

Chee Kai Chua

School of Mechanical and Production Engineering, Nanyang Technological University, Nanyang Avenue, 639798 Singapore, Singapore

2 Temasek Polytechnic, Tampines, Singapore 